\title{
Myths and Stereotypes: The Lived Experiences of People with Albinism
}

\author{
Fiasorgbor Doris \\ Department of Rural and Community Development, Presbyterian University College, Ghana, Akropong
}

Email address:

dfiasorgbor@presbyuniversity.edu.gh

\section{To cite this article:}

Fiasorgbor Doris. Myths and Stereotypes: The Lived Experiences of People with Albinisma. Psychology and Behavioral Sciences. Vol. 8, No. 3, 2019, pp. 61-66. doi: 10.11648/j.pbs.20190803.11

Received: March 29, 2019; Accepted: May 8, 2019; Published: June 24, 2019

\begin{abstract}
The phenomenon of Albinos being treated badly is a growing concern in many Africa countries. Ghana is not an exception to the general trend of Albinos being discriminated against. However, very little is known about this unique population in Ghana. For most societies, albinism is hardly (or not) understood. Myths and misconceptions surround the condition, a common characteristic of albinos is that they experience stigma as people with white skin in black societies. Stigma and discrimination are sources of depression, guilt and anger among persons with Albinism. This study was conducted in Bolgatanga Municipality. The study employed a mixed method approach where both qualitative and quantitative techniques were espoused. The study used the probability and non-probability sampling methods to select the participants of the study. Simple random sampling technique was used to select thirty (31) albino participants. The study found that the outward appearance, myths and perception of people that Albinos wounds or sores do not heal exposed them to stigmatisation and discrimination in the community. Teasing and name calling are some of the difficulties Albinos in Bolgatanga face which sometimes leads to depression and frustrations. Based on the findings the study recommends that teachers and parents should encourage their Albino pupils/wards to stay in school and sensitization programs concerning Albinism should be introduced in schools to create awareness of the conditions to pupils so that they can accept their fellow students who are Albino.
\end{abstract}

Keywords: Albinism, Myths, Realities, Lived Experiences, Bolgatanga

\section{Introduction}

Albinism is a genetic condition where a person lacks the gene for generating melanin - the pigment that shields the skin from ultraviolet light from the sun. Persons with albinism (PWA) may lack pigment in the skin, eyes and hair. The exact incidence of albinism in the human race is not clear but estimates claim the ratio could be nearly 1 in 17,000 [1]. In Africa, the range is from 1 in 5,000 to 1 in 15,000 [2].

There are various types and sub-types of albinism defined by the degree to which there is a lack of melanin and what body parts are affected [3]. For most societies around the globe, albinism is scarcely (or not) understood. Myths and misconceptions surround the condition; a common feature of albinos is that they experience stigma as people with white skin in black societies, as people with disabilities, of low vision or blindness and vulnerable to contracting skin cancers. The greatest health and social concerns for Africans with albinism affect their education, social inclusion, life chances and security. This is augmented in many parts of sub-Saharan Africa; basically because the condition is thought of as evil, a curse, or as some form of punishment from the gods or the ancestors for something wrong done by the parents [4].

According to Thuku [5] stigma and discrimination are sources of depression, guilt and anger among persons with Albinism. Due to the negative societal attitudes towards persons with Albinism they have high chances of dropping from school and this lessens the opportunities for them to be gainfully employed in the near future. The negative cultural beliefs have a negative impact on the rights of Albinos. They include the belief that their body parts can be used in witchcraft to bring wealth and prosperity hence contributing to their high murder and mutilation of persons with the condition.

Albinos are human beings that should enjoy their lives just like any other person, however in Ghana, specifically in Bolgatanga, and other countries in Africa this is not the case 
as some of them are facing various psychosocial challenges that include stigma and discrimination resulting in social exclusion and low self-esteem. Social exclusion has also resulted in Albinos' needs not featuring on the national agenda which negatively affect their access to social amenities. Stigmatization and discrimination among persons with OCA have also resulted in emotions that include anger, depression and a guilty conscience. Faced with these challenges, Albinos in Bolgatanga use various strategies that range from seeking social support and releasing emotional tension through crying. Persons with albinism may tend to avoid social situations as a negative strategy of stigma and discrimination. It is against this background that the study investigated the myths and realities of Albinism in Bolgatanga. The main objective of the study is to investigate the lived experiences of people with Albinism in Bolgatanga. The specific objectives are; to assess the perception, attitudes, emotions, behaviours, and beliefs associated with albinism in Bolgatanga; to establish the psychosocial challenges that Albinos face in Bolgatanga and to know the coping strategies employed by Albinos. This study investigated the psychosocial challenges, myths and realities of Albinos and their coping strategies.

\section{Methodology}

\subsection{Area of Study}

This study was conducted in Bolgatanga Municipality. Bolgatanga, colloquially known as Bolga, is one of the fifteen (15) districts/municipalities in the Upper East Region. It is centrally located in the region (see Figure 1). Bolgatanga serves as both the municipal and regional capital. It is one of the two municipalities in the region. The population density is relatively higher than the national figures, with much of it clustered around the municipal capital. About half (50\%) of the population is rural and $44 \%$ of the people under age 18 years. There are about 213 communities in the Municipality, most of which are rural. The ethnic composition of Bolgatanga is cosmopolitan, but the indigenes are the Gurune speaking people [6].

According to the 2010 PHC, the Bolgatanga Municipality recorded 3,885 persons with various types of disability, being $3 \%$ of the district's population of 131,550 persons $(48 \%$ male and $52 \%$ female). The literature suggests that more than half (55\%) of all PWDs in the Municipality do not have formal education and only $1 \%$ had some form of vocational/technical or commercial education [6]. This is an indication that PWDs in the Municipality are unlikely to be employable and therefore poorer than their non-disabled counterparts. This is further worsened by low societal expectations of their capabilities combined with architectural barriers, lack of access to transportation, lack of information, inadequate and special educational facilities, inadequate medical systems, negative cultural beliefs and practices. The Majority of PWDs are also likely to find themselves in rural communities where negative attitudes are likely to be more prevalent.

In the Bolgatanga municipality, myths about Albinism is so rampant that some young ones have grown to believe in those stories about Albinos without fact. This does not apply to only people who are not educated or highly educated but also the educated. Due to the myths and negative attitude of people towards Albinos, it is rare to see them during the day even though there are a lot of Albinos in the Bolgatanga community.

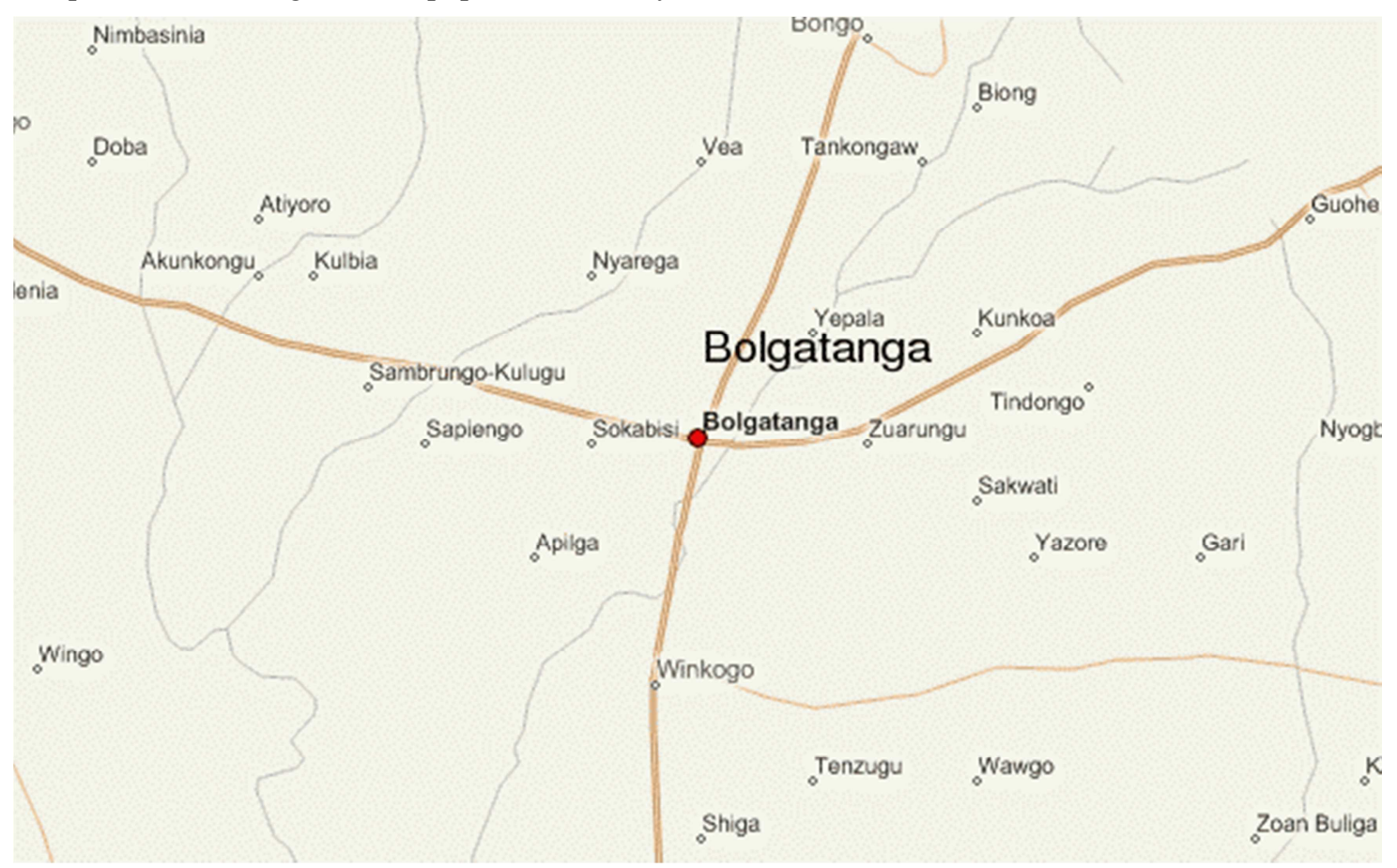

Figure 1. Map of Upper East Region showing Bolgatanga/Source: BMA, 2018. 
The study used a mixed method where both qualitative and quantitative techniques were employed. The study used the probability and non-probability sampling methods to select the participants of the study. Simple random sampling technique was used to select thirty (31) albino participants for the study. A membership list with phone numbers of hundred and thirty (130) members from the Disabled and Albino Association formed the frame from which thirty (30) respondents with albinism were selected for the study. Each name on the register was assigned a number and the numbers were put in a hat to select the thirty (30) respondents. A purposive sampling, a non-probability sampling method was used to target five (5) key informants and ten (10) participants for the two (2) focus group discussions. Data was collected between October and December, 2018.

\subsection{Ethical Consideration}

Informed consent was sought from community leaders and study participants. Great care was taken to include only those who consented and the information part of the informed consent was taken very seriously. All the study participants were repeatedly told the purpose and methods of the study. Care was taken to exclude those who either failed to understand the purpose of the study or did not consent to the study.

\subsection{Conceptual Framework}

The conceptual framework below outlines the networks through which the myths and realities of albinism could be unwritten better. The myths and realities of albinism depend on the society (e.g. teasing and name calling, discrimination, stimatisation, anger and frustration, and low self-esteem). Drawing from existing literature, the researcher conceptualised that the perception and attitude of society toward albinos would be contributing factors to the eventual low self-esteem of the PWAs. In a parallel vein, Dogbe et al. [7] posited that an attitude is a predisposition to respond positively or negatively towards a particular idea, object, person, or situation and this influence a person's choice of action. He noted that attitudes have four (4) major components that is "affective which include emotions and feelings, cognitive which include belief or opinions held consciously, conative which is inclination for action and evaluative which include a positive or negative response to stimuli". Persons with Oculocutaneous albinism have been exposed to both positive and negative attitudes from the society and this has determined their levels of selfesteem.

\subsubsection{Teasing and Name Calling}

Teasing and name-calling may be interpreted as a means by which to oppress people with albinism. Certain words function to describe someone in a derogatory way, which in turn oppresses and hurts the individual in question. It has also been argued that name-calling has the effect of excluding people from normal social life [8].

\subsubsection{Stigma and Discrimination}

Stigma is seen as the holding of derogatory social attitudes or cognitive beliefs that radically changes the way people view themselves or the way they are viewed by others and discrimination on the other hand is defined as the negative actions towards those people [9].

\subsubsection{Anger and Frustration}

Mapimhidze, [10] viewed emotions as experiences that include a subjective feeling, a cognitive interpretation, a physical reaction and behavioural expression for example anger, depression and guilt. Internalisation of these feelings reinforces feeling of low self-esteem among persons with OCA.

\subsubsection{Low Self-Esteem}

Self-esteem refers to individual's perception or subjective appraisal of one's own self-worth, one's feelings of selfrespect and self-confidence and the extent to which the individual holds positive or negative views about self [11]. Self-esteem is related to personal beliefs about skills, abilities, and social relationships. Self-esteem is also defined as a global barometer of self-evaluation involving cognitive appraisals about general self-worth and affective experiences of the self that are linked to these global appraisals [12]. By the same token, [13] stated that self-esteem involves an evaluation of oneself followed by an emotional reaction towards oneself.

\section{Results}

\subsection{Demographic Information}

The participants' demographic information presented is the sex of the participants, age, marital status and occupation. The study found that seven (7) participants (23\%) were between the ages of 9-18, fifteen (15) participants (48\%) were between the ages of 19 and 28years and nine (9) participants $(29 \%)$ were between the ages of 29 and 38 years old. In total thirty (31) albino participants were interviewed. From the data collected, the researcher concludes that most albinos in Bolga are between the ages of 19-28years which shows the highest percentage of $48 \%$ with an average age being 30years old. Majority (58\%) of the participants (albinos) were males and $42 \%$ were females. The study found that $28 \%$ respondents went to school up to primary level, $3 \%$ showed that they are in Junior High Schools (JHS), 9\% were in Senior High Schools (SHS) and 16\% had attained tertiary level education. $6 \%$ had no formal education and $25 \%$ had no education at all.

From the study conducted, majority of Albinos were students in the basic and second cycle institutions (primary, JHS and SHS) albino enrolment at the SHS level was very low; this could be that, at the earlier stages of education some parents were able to compel their Albino children to go to school but as they reach higher levels, the children begin to feel the pain of name calling and teasing by their colleagues, 
and sometimes by some adults too, as a result they begin to drop out of school. For those who were able to make it to the tertiary level were people who are from educated and well to do homes; where their parents were able to convince them that the condition of Albinism is normal and always stood by them both emotionally and financially. This could be associated with the high percentage of trade occupation, thus from the study, the researcher found out that, most of the Albino traders were school dropouts. Albinos find it difficult getting into relationships; whether it is friendly or romantic, not to talk of marriage. Most at times, it is the ladies who find it difficult getting a partner. This is as a result of the myths and perception of people about albinism and the skin and hair colour. Out of the thirty one (31) albino respondents, a majority $(63 \%)$ of the participants were single, $31 \%$ was married and 3\% person was divorced, making a total of $97 \%$. The rest of the participants $(3 \%)$ refused to disclose their marital status, saying it was personal information they would. One participant in the Junior High School student revealed that "a man impregnated me, it was my first time of getting into a relationship, but he abandoned me immediately he noticed that I was pregnant". Most of the Albino women associated their singleness to their condition. However, the study also found that male Albinos did not face relationship or marriage difficulty.

\subsection{Knowledge About Albinism}

Data reveals that most of the participants including some of the Albino participants (87\%) did not know the causes of Albinism. They either attributed it to witchcraft, a curse or a punishment from the ancestors or gods. However, 13\% Albinos had knowledge on the causes of Albinism; they attributed it to something normal and naturally made by God, and others said it is the lack of a pigment called melanin that causes the change of colour and skin.

\subsection{Albinos Do Not Die Natural Death}

Most (59\%) of the non-albino participants were of the view that albinos do not die naturally. They indicated that though they have never witnessed an Albino vanish; they believe it because they have also never witnessed an albino's funeral. Respondents could not say much about this issue but indicated that this is what they have been hearing about Albinos; which is one of the myths that are associated with Albinism.

\subsection{Effects of Albinism on Economic Activities}

As albino traders, the nature of their skin scares customers who come around to buy things. Sometimes when traders are seated at their shops and customers walk into the shop, as soon as they rise to serve them; once the customers see an Albino coming to serve them, they usually give excuses and just walk away without coming back. Even though this attitude affects business, the albinos revealed that they still have customers who patronise their businesses regardless of their skin colour.

\subsection{Community Attitude Towards Albinos}

Responses of non-albino respondents to support or reject the claim that the body parts of Albinos can be used for rituals to bring wealth and prosperity showed that $66 \%$ of the respondents agreed while $28 \%$ disagreed and $6 \%$ did not know whether it was true or not. Most of the respondents said that they have been heard stories about Albino and hunchback people's body parts being used for money rituals that bring about wealth and prosperity. However, it was revealed that the people who use Albinos body parts for rituals were not from the municipality.

All the Albinos revealed that stigma and discrimination is their greatest challenge in Bolgatanga. They said, they are seen as scary and smelly people, smelly because Albinos have lesions which do not heal fast thereby making them have strange body odour, thus, people do not want to associate with Albinos. Albinos in Bolga also face stigmatisation issues such as demeaning name calling whenever they went out during the day. One of the Albinos had this to say;

The community people say a lot of untrue things about us that make us feel very bad and unwanted. They have this myth that we do not die and we do not go to the toilet on Fridays. The community members have been calling us by demeaning and dehumanizing names such as Poor Whiteman or woman, Walking fire, White Ghost Yaazi meaning roasted groundnut powder and Rejected European.

The study found that Albinos in the Bolga turn to express a lot of anger and frustrations at these attitudes towards them because they see themselves as not being like other people in the society and cannot live normal community life just like any other person. A non-Albino respondent indicated that "naturally those Albinos are scary, so I do not want to have anything doing with them". Another Albino respondent stated that;

There is a house on my way to school, in this house is a little boy who always cry and scream whenever I pass by the house. This is as a result of my appearance as an albino. I really feel bad about it because even a kid like her can tell that I am different from the other members of the community".

Stigmatisation and discrimination has made Albinos have low self-esteem in society, they are made to feel the pain of rejection by community members and sometimes by family members. The table 1 below presents some of the demeaning names Albinos are called in the Bolga.

Table 1. Demeaning names of Albinos.

\begin{tabular}{lll}
\hline Walking fire & Fire on the mountain run & Red bat \\
\hline Korea citizen & White ghost & Bad colour \\
Jartoe & Fire fly & Scary people \\
Ofiri & Rejected European & Yaazi \\
Poor Whiteman or woman & Smelling people & Traffic \\
Fire service & Red-light & Unclean \\
Tanzania Bogar & Mulato & Dazaar \\
Friday & Bad luck & Monkey \\
\hline
\end{tabular}




\subsection{Need for Skin Cancer Treatment Centre}

Both Albinos and non-albino participants in the community indicated that there was a need for a skin cancer treatment unit in the regional hospital for albinos; so they can be treated whenever they have a problem with their skin. This is to prevent continuous stigmatisation and disassociation by other patients and some nurses whenever they went to the hospital. Also participants said there is no known treatment centre for Albinos in the municipality, majority of them felt there was the need to have a centre for the treating Albinos; since they most often face discrimination when they go to the regular hospitals for treatment. Health workers revealed that having a special unit for treating Albinos would be helpful because sometimes the so called discrimination by health workers as perceived by Albinos is not really the case. They said treating an Albino feels same as treating any other person.

\subsection{Coping Strategies}

The study established that most of the Albinos could not do anything when they face discrimination and stigma. The few children in school, especially the boys either beat their mates to stop the name calling, and the weaker ones either report to the teachers, cry as they run home to report to their parents and others did virtually nothing about it, the pupil who cannot express themselves, drop out of school and some of the adult Albinos also insult people who call them by demeaning names while others just walk away without doing anything.

\section{Discussion}

The outward appearance, myths and perception of people that Albinos wounds or sores do not heal, thereby causing them to develop body odour which expose them to stigmatisation and discrimination in the community. This is in line with the findings of Alum et al. [14] which revealed that most people with albinism have been indiscriminately alienated and stigmatised in their own communities. They have been the items of wonder, ridicule, superstition and scorn in the society. This is basically because the community members are not enlightened on the conditions of Albinism but have based their knowledge on the myths that have been passed on by their forefathers and our grandfathers who do not know exactly the causes of Albinism but attribute it to curses, misfortune and other untrue stories.

It is difficult for Albinos to find marriage partners in Bolga. The findings of this study confirms the assertion by Cruz-Inigo et al. [15] that stigma and social discrimination of persons with Oculocutaneous albinism cuts across various spheres of their lives which include the marriage institution, where persons with oculocutaneous albinism have been denied the right to start their own stable families. Also, Brocco [16] said that PWAs have been neglected, with no friends and acceptance even in their own community and schools. Sharing utensils, places and even public facilities are restricted in communities that still believe that albinism is contagious. Because of this segregation, most people with albinism find it difficult to have marital partners. However, contrary to their findings, Albino men in Bolga do not find it as difficult as their female counterparts.

Teasing and name calling are some of the problems Albinos in Bolgatanga face and sometimes it leads to depression and frustrations. Gronskov \& Nielson [17] in a related study reached similar conclusions where he established that derogatory and demeaning terminology for PWA has led to prejudice and stereotypes. This he said constitutes emotional abuse which has sometimes affected negatively the self-worth and dignity of persons with OCA. These derogatory and humiliating names imply that persons with albinism are lesser beings.

\section{Conclusion and Policy Recommendation}

\subsection{Conclusions}

The study investigated the myths and realities of Albinism in Bolgatanga. From the findings it showed that there are myths and false stories related to Albinism which leads to stigmatisation and discrimination in the society. Due to the untrue stories passed on from the past generation to the present ones, people turn to call Albinos by so many demeaning names. All these demeaning names make Albinos feel they are not human because of the colour of their hair and skin thereby leading to low self-esteem. Because of the stigma, discrimination, teasing and name calling, pupils, especially in the basic schools dropout of school to join their mothers in the market.

\subsection{Recommendations for Policy and Practice}

Based on the above findings from the study, the following are the recommendations made:

1. Teachers and parents should encourage their Albino pupils/wards to stay in school.

2. Sensitization programs concerning Albinism should be introduced in schools to create awareness of the conditions to pupils so that they can accept their fellow students who are Albino.

3. There should be advertisement on TV and radio stations on the laws regarding the right of Albinos in the country.

4. The law, thus Article 17 (2), Ghana's 1992 constitution which says "A person shall not be discriminated against on grounds of gender, race, colour, ethnic origin, religion, creed or social or economic status" must be enforced to protect Albinos from stigma and discrimination.

5. The elderly in our traditional society should avoid passing on untrue and non-factual stories about Albinism to the younger ones to avoid stigma and discrimination. 


\section{Acknowledgements}

The author is grateful to the people of Bongo and the Presbyterian University College, Ghana. Thanks to Ms Matilda Ayeltige who collected and organised the data.

\section{References}

[1] Wiete, W. (2011). Life of albinos in East Africa threatened: A most bizarre and dramatic consequence of having a skin colour disease.

[2] Schühle, J. (2013). "Medicine Murder of People with Albinism in Tanzania - How Casino Capitalism creates Rumorscapes and Occult Economies." CAS Working Paper Series, Center for Area Studies, Freie Universität Berlin, 2: 335 .

[3] The National Organization for Albinism and Hypopigmentation (NOAH). (2017)

http://www.albinism.org/site/c.flKYIdOUIhJ4H/b.9260359/k.

EB45/Information Bulletin Social_Aspects of Albinism.htm. Accessed $7^{\text {th }} \overline{\text { March }} 2019$.

[4] Burke, J. (2012). Discrimination and violence against Tanzanians with albinism in the Great Lakes region: crime and national shame - A paper presented at the 35th AFSAAP Annual Conference. Accessed 3/12/13 http://afsaap.org.au/assets/BURKE.pdf

[5] Thuku, M. (2011). Myths, discrimination, and the call for special rights for persons with albinism in sub-Saharan Africa. In Amnesty International editorial review on Special Programme on Africa.

[6] Bolgatanga Municipal Assembly (2012). The Composite Budget ofthe Bolgatanga Municipal Assembly for the 2012 Fiscal Year. Bolgatanga.

[7] Dogbe J, Owuusu-Dabo E, Edusei A, Plange-Rhule G, Addofoh N, BaffourAwuah A, Sarfo-Kantanka O, Hammond C, Owusu M. (2016) Assessment of prison life of persons with disability in Ghana. BMC Int Health Hum Rights.

[8] Burke, J., Kaijage, T. J., \& John-Langba, J. (2014). Media analysis of albino killings in Tanzania: A social work and human rights perspective. Ethics And Social Welfare, 8 (2), 117-134. doi: 10.1080/17496535.2014.895398
[9] United Nations Human Rights Council (2013). Attacks and discrimination against people with albinism. http://www.un.org/en/ga/search/view_doc. asp Accessed 1st May 2019.?symbol=A/HRC/RES/23/13.

[10] Mapimhidze, R. (2011): The Agony of Being an Albino. Available online at ww.newsday.co.zw/article/2011-07-20-theagony-of-being-an-albino. Accessed $30^{\text {th }} 2019$.

[11] Protogerou C, Flisher A (2012). Bullying in schools. In: A van Niekerk, S Suffla, M Seedat (Eds.): Crime, Violence and Injury in South Africa: 21st Century 124 CLEVER NDEBELE AND DUDU MSIZA Solutions for Child Safety. Tygerberg: MRC, pp. 119- 133.

[12] Machoko, C. G. 2013. "Albinism: A Life of Ambiguity - A Zimbabwean Experience.” African Identities 11 (3): 318-333.

[13] Baker, C., Lund P, Nyathi, R. \& Taylor, J. (2010). The myths surrounding people with albinism in South Africa and Zimbabwe. African Cultural Studies 22 (2): 169-181

[14] Me'Dard Djatou. (2009). “The 'Wrong' Colour? Representations and Perceptions of Albinism among the Bamileke of Western Cameroon," in Expressions of the Body: Representations in Africa Text and Image (pp. 123-128).

[15] Oakford, S. (2014) Fuelled by superstition, people are violently attacking lbinos in Tanzania. Accessed 23/09/2014. https://news.vice.com/article/fueled-by-superstition-peopleare-violently-attacking-albinos-in-tanzania. Accessed $30^{\text {th }}$ 2019.

[16] Alum, A. Gomez, M., and Ruiz E. (2009). Hocus Pocus, Witchcraft, and Murder: The Plight of Tanzanian Albinos. Chicago: Northwestern University of Law.

[17] Cruz-Inigo, A. E., Ladizinski, B., \& Sethi, A. (2011). Albinism in Africa: Stigma, Slaughter and Awareness

[18] Brocco, G. 2015. "Labelling albinism: Language and discourse surrounding people with albinism in Tanzania." Disability and Society $30(8): 11431157$.

[19] Kiprono, S. K., Joseph, L. N., Naafs, B., and Chaula, B. M. (2012). Quality of Life and People with Albinism in Tanzania: More than Only A Loss of Pigment. Journal of Scientific Reports Vol. 1: 2-83. 